\title{
Time to re-appraise the role of alpha-1 adrenoceptor antagonists in the management of hypertension?
}

\author{
Neil Chapman ${ }^{a}$, Chung-Yin Chen ${ }^{b}$, Toshiro Fujita ${ }^{c}$, F.D. Richard Hobbs ${ }^{d}$, \\ Soo-Joong Kim ${ }^{\mathrm{e}}$, Jan A. Staessen ${ }^{\mathrm{f}}$, Supachai Tanomsup ${ }^{\mathrm{g}}$, Ji-Guang Wang ${ }^{\mathrm{h}}$ and \\ Bryan Williams ${ }^{i}$
}

The role of alpha-1 adrenoceptor antagonists (alphablockers) in the management of hypertension continues to evolve. Recent data support their use as add-on therapy in uncontrolled hypertension when used in combination with all other major classes of antihypertensive drug and there is increasing evidence suggesting that they have modest but significant beneficial effects on lipid and glucose metabolism. The availability of extended-release formulations has contributed to an excellent tolerability profile. New data from an observational analysis of the Anglo-Scandinavian Cardiac Outcomes Trial (ASCOT) suggest that doxazosin gastrointestinal therapeutic system (GITS) used as a third-line antihypertensive agent lowered blood pressure and caused modest reductions in plasma lipids.

Furthermore, use of doxazosin in ASCOT was not associated with an increased risk of heart failure, in contrast to the earlier finding of the Antihypertensive and Lipid-Lowering Treatment to Prevent Heart Attack Trial (ALLHAT). Overall, currently available data support the use of alpha-blockers as safe, well tolerated and effective add-on antihypertensive drugs, which have additional favourable metabolic effects. J Hypertens 28:1796-1803 (c) 2010 Wolters Kluwer Health | Lippincott Williams \& Wilkins.

Journal of Hypertension 2010, 28:1796-1803
Keywords: alpha-blockers, doxazosin, gastrointestinal therapeutic system, hypertension, metabolic effects

Abbreviations: ACE-I, angiotensin-converting enzyme inhibitor; ALLHAT, Antihypertensive and Lipid-Lowering Treatment to Prevent Heart Attack Trial; Apo, apolipoprotein; ASCOT, Anglo-Scandinavian Cardiac Outcomes Trial; BP, blood pressure; CCB, calcium channel blocker; CHD, coronary heart disease; $\mathrm{CHF}$, congestive heart failure; $C_{\max }$, maximum concentration; $C_{\text {min }}$, minimum concentration; GATES, Doxazosin GITS as Add-on Therapy in Hypertension: an Efficacy and Safety Study; GITS, gastrointestinal therapeutic system; HALT, Hypertension and Lipid Trial; HDL-C, high-density lipoprotein cholesterol; HOMA, homeostasis model assessment; JNC, Joint National Committee on Prevention, Detection, Evaluation, and Treatment of High Blood Pressure; LDL-C, low-density lipoprotein cholesterol; MCR, metabolic clearance rate; NICE, National Institute for Health and Clinical Excellence; NS, no significant change; SNS, sympathetic nervous system; SSPG, steady-state plasma glucose; $T_{\max }$, time to maximum concentration; TOMHS, Treatment of Mild Hypertension Study; Total-C, total cholesterol

anternational Centre for Circulatory Health, Imperial College, London, UK ${ }^{b}$ Kuang-Tai-chung General Hospital, Kuang-Tai-chung, Taiwan, ' University of Tokyo School of Medicine, Tokyo, Japan, dPrimary Care Clinical Sciences, University of Birmingham, Birmingham, UK, e'Division of Cardiology, Kyunghee University Medical School, Seoul, Korea, 'Division of Hypertension and Cardiovascular Rehabilitation, Department of Cardiovascular Diseases, University of Leuven, Leuven, Belgium and Department of Epidemiology, Maastricht University, Maastricht, The Netherlands, ${ }^{9}$ Ramathidbodi Hospital, Mahidol University, Bangkok, Thailand, ${ }^{\mathrm{h} C e n t r e}$ for Epidemiological Studies and Clinical Trials, Ruijin Hospital, Shanghai, China and 'University of Leicester School of Medicine, Leicester, UK

Correspondence to Dr Neil Chapman, International Centre for Circulatory Health, Imperial College London, 59 North Wharf Road, London W2 1PG, UK Tel: +44 207594 1082; fax: +44 207594 1386; e-mail: neil.chapman@imperial.nhs.uk

Received 14 January 2010 Revised 6 April 2010 Accepted 29 April 2010

the study was terminated prematurely due to a significantly higher incidence of combined major cardiovascular disease events, particularly an increased risk of congestive heart failure (CHF), among those randomized to doxazosin compared with chlorthalidone [21]. Consequently, in the Seventh Report of the Joint National Committee on Prevention, Detection, Evaluation, and Treatment of High Blood Pressure (JNC 7) guidelines, alpha-blockers were not recommended for the routine treatment of hypertension [22]. This has had a major impact on their use for the treatment of hypertension worldwide.

Recent data on the mechanism of action of alpha-blockers have emerged from experimental studies [23,24] and new clinical studies have confirmed their BP-lowering efficacy [25,26]. Results of an observational analysis from the Anglo-Scandinavian Cardiac Outcomes Trial 
(ASCOT) [27] have demonstrated the effectiveness of doxazosin and called into question the conclusions of the ALLHAT investigators, prompting a reappraisal of the role of alpha-blockers for the treatment of hypertension.

The clinical narrative review presents an update on the evolving role of alpha-blockers in the management of hypertension. Clinical data on all selective alpha-1 blockers are included, with most data available for doxazosin, the principal reference agent for the class and the alphablocker most commonly used for the treatment of hypertension.

\section{Mechanism of action of alpha-blockers}

Cardiovascular regulation by the sympathetic nervous system (SNS) is mediated via activation of one or more subtypes of the adrenergic receptor family, including alpha- 1 and alpha-2 receptors, classified according to their response to epinephrine and norepinephrine. Blockade of alpha-1 receptors provides a rational approach to the treatment of hypertension by inhibiting the binding of noradrenaline, thereby promoting smooth muscle cell relaxation, reduced vascular tone and decreased peripheral resistance [28]. Early tolerability issues, for example, due to postural hypotension associated with unfavourable pharmacokinetics of immediate-release drugs, have been largely overcome by the development of controlledrelease formulations, such as prazosin and doxazosin gastrointestinal therapeutic system (GITS) [29-32]. Such formulations have been designed to improve the drugs' pharmacokinetic profiles and to minimize side effects by slowing absorption and reducing fluctuations in plasma concentration [30]. The pharmacokinetic characteristics of standard and long-acting formulations of alpha-blockers commonly prescribed for the treatment of hypertension are shown in Table 1 [29-32].

\section{Alpha-blockers and blood pressure control}

The BP-lowering effects of selective alpha-blockers have been extensively studied, both as monotherapy and in combination with other antihypertensive drug classes.

Table 1 Pharmacokinetic characteristics of standard and long-acting formulations of selective alpha-1 receptor antagonists

\begin{tabular}{llll}
\hline Drug & Characteristic & Standard & GITS \\
\hline Terazosin [29] & $T_{\max }$ & $1 \mathrm{mg} ; 1.7 \mathrm{~h}$ & - \\
& $C_{\max }$ & $1 \mathrm{mg} ; 15.5 \mathrm{ng} / \mathrm{ml}$ & - \\
Prazosin [31] & Mean residence & $4 \mathrm{mg} ; 10.8 \mathrm{~h}$ & $2.5 \mathrm{mg} ; 21.6 \mathrm{~h}$ \\
& time & & $5 \mathrm{mg} ; 22.5 \mathrm{~h}$ \\
Doxazosin [32] & $T_{\max }$ & $4 \mathrm{mg} ; 3.7 \mathrm{~h}$ & $4 \mathrm{mg} ; 8.2 \mathrm{~h}$ \\
& & $8 \mathrm{mg} ; 3.9 \mathrm{~h}$ & $8 \mathrm{mg} ; 9.1 \mathrm{~h}$ \\
& $C_{\max }$ & $4 \mathrm{mg} ; 29.3 \mathrm{ng} / \mathrm{ml}$ & $4 \mathrm{mg} ; 11.3 \mathrm{ng} / \mathrm{ml}$ \\
& & $8 \mathrm{mg} ; 66.8 \mathrm{ng} / \mathrm{ml}$ & $8 \mathrm{mg} ; 28.0 \mathrm{ng} / \mathrm{ml}$ \\
& $C_{\min }$ & $4 \mathrm{mg} ; 7.4 \mathrm{ng} / \mathrm{ml}$ & $4 \mathrm{mg} ; 6.4 \mathrm{ng} / \mathrm{ml}$ \\
& & $8 \mathrm{mg} ; 19.0 \mathrm{ng} / \mathrm{ml}$ & $8 \mathrm{mg} ; 17.8 \mathrm{ng} / \mathrm{ml}$ \\
\hline
\end{tabular}

$T_{\max }$, time to maximum concentration; $C_{\max }$, maximum concentration; $C_{\min }$, minimum concentration; GITS, gastrointestinal therapeutic system.
Studies of prazosin, terazosin, alfuzosin and doxazosin have reported similar BP-lowering efficacy to other therapies when used as monotherapy [1-8]. Following 12 weeks of treatment, standard-release formulations of both prazosin and doxazosin decreased BP in approximately $70 \%$ of patients with hypertension, with no difference between treatments [1]. Alfuzosin (not licensed for use in hypertension in the UK or US) was as effective as propanolol when used first line [2]. In a large communitybased study, terazosin monotherapy significantly lowered $\mathrm{BP}$ with similar efficacy to diuretics, beta-blockers, CCBs and ACE inhibitors; among patients who had not responded to monotherapy with these other drugs, the addition of terazosin resulted in significant $\mathrm{BP}$ reductions [3]. Prazosin GITS was shown to have similar BP-lowering efficacy to enalapril in patients with hypertension and diabetes [4]. After 4 years of follow-up in the randomized Treatment of Mild Hypertension Study (TOMHS), initial therapy with standard-release doxazosin (1-2 mg per day) reduced systolic and diastolic BP by 13.4 and $11.2 \mathrm{mmHg}$, respectively, compared with mean reductions of $8.6 \mathrm{mmHg}$ for both systolic and diastolic $\mathrm{BP}$ among those who received placebo [5]. In a 12-week placebo-controlled trial, the Doxazosin Investigators' Study Group found that 68 and $64 \%$ of patients with mild-to-moderate hypertension achieved BP targets with standard (1-8 mg per day) and GITS (4-8 mg per day) formulations of doxazosin, respectively, compared with $36 \%$ in the placebo group [6]. Other trials of doxazosin monotherapy (both standard and GITS formulations) have demonstrated significant $\mathrm{BP}$ reductions with a favourable safety profile $[7,8]$ and doxazosin has been shown to be effective and well tolerated as add-on therapy in uncontrolled hypertension [9].

The timing of doses of alpha-blockers may affect their efficacy. Doxazosin GITS achieved more effective 24-h BP control when administered (either as add-on or monotherapy) at night rather than in the morning [33]. In this 3-month study, a single dose of doxazosin GITS administered at bedtime achieved significantly better 24-h BP control compared with morning dosing, possibly by more effectively reducing the prewaking activation of the SNS. In a substudy of the Hypertension and Lipid Trial (HALT), evening dosing with doxazosin reduced both daytime and night-time systolic and diastolic BP, with potentially favourable effects on nocturnal BP-dipping patterns [34].

\section{Metabolic actions of alpha-blockers}

In addition to lowering $\mathrm{BP}$, alpha-blockers have been shown to exert a variety of potentially beneficial effects on lipid and glucose metabolism. These include reduced total cholesterol, low-density lipoprotein (LDL) cholesterol and apolipoprotein (Apo) B concentrations, reduced oxidation of LDL cholesterol, increased high-density lipoprotein (HDL) cholesterol and Apo A-1 concentrations, 
reduced hyperinsulinaemia and an improvement in glucose tolerance [3,4,10-19]. The metabolic effects of alphablockers used as monotherapy in recent trials that included at least 100 patients are summarized in Table 2. Favourable effects on lipid profiles have also been demonstrated when alpha-blockers have been used in combination with other classes of antihypertensive agents [3] and on insulin sensitivity when used in combination with acarbose in patients with impaired glucose tolerance [19]. The molecular mechanisms underlying the metabolic effects have been explored and recent evidence suggests that doxazosin may increase HDL cholesterol biosynthesis by mechanisms involving gene transcription that are independent of its alpha-1 receptor antagonist properties [24].

\section{Safety and tolerability of alpha-blockers}

Alpha-blockers are generally well tolerated and have similar adverse event profiles to other antihypertensive agents [1-4]. Terazosin was well tolerated in more than 16000 patients with a variety of concomitant diseases, including $\mathrm{CHF}$, peripheral vascular disease, chronic obstructive pulmonary disease, diabetes and obesity [3]. Adverse events were reported in $18 \%$ of patients, most frequently dizziness (5\%), headache $(3 \%)$, and asthenia (2\%). Only 0.4 and $0.2 \%$ of patients experienced syncope and impotence, respectively, and only $2 \%$ dropped out of the study because of adverse events. Standard-formulation doxazosin has an incidence of adverse events similar to placebo, with minor adverse effects such as headache and dizziness being most commonly reported $[9,25]$. In TOMHS, doxazosin compared favourably with other antihypertensive drugs with regard to erectile dysfunction in men; the incidence decreased by $6 \%$ compared with a $10 \%$ increase among those randomized to chlorthalidone [35]. Doxazosin GITS is also well tolerated $[7,8,26]$ with fewer discontinuations than with the standard formulation or placebo [6].

\section{The impact of ALLHAT}

Antihypertensive and Lipid-Lowering Treatment to Prevent Heart Attack Trial was designed to compare the effects of chlorthalidone (a thiazide-like diuretic) with an alpha-blocker (immediate-release doxazosin), a CCB or an ACE inhibitor among hypertensive patients (aged $\geq 55$ years with at least one other vascular risk factor) [21]. Overall, 42424 participants were randomized, of whom 15268 received chlorthalidone and 9067 received doxazosin.

Follow-up was planned for 4-8 years. However, the doxazosin arm of the trial was discontinued prematurely following an interim data safety review. This decision was based on a significantly higher incidence of combined cardiovascular disease events (a secondary endpoint) among participants in the doxazosin arm as well as a low likelihood that a difference in the primary endpoint would be observed by the scheduled trial end [21].
Chlorthalidone provided superior BP-lowering efficacy to doxazosin at the doses used (12.5-25 and 2-8 $\mathrm{mg}$, respectively) with systolic BP lower by an average of $3 \mathrm{mmHg}$. Neither the primary endpoint of fatal CHD or nonfatal myocardial infarction [relative risk (RR) 1.03, $95 \%$ confidence interval (CI), 0.90-1.17] nor total mortality (RR 1.03 , 95\% CI 0.90-1.15) differed between the two groups. However, major cardiovascular events were $25 \%$ more frequent among those assigned doxazosin (RR 1.25, 95\% CI 1.17-1.33), a result driven by higher rates of stroke (RR 1.19, 95\% CI 1.01-1.40) and particularly CHF (RR 2.04, 95\% CI 1.79-2.32).

Interpretation of these data has varied widely. Some concluded that doxazosin should be used only as addon therapy, whereas one editorial questioned even this use [36]; others, meanwhile, questioned the rationale behind early termination of the trial (which itself may have exaggerated any true difference in outcomes between treatment arms). It has been argued that the observed effects on stroke (as well as some of the effect on heart failure) are potentially consistent with the observed BP differences [37], which themselves may be related to the use of suboptimal doses of the shortacting version of doxazosin.

The heart failure results in particular have provoked much debate. Commentators have questioned the validity of heart failure diagnoses, particularly given that the high rates of heart failure observed $(2.8$ and $5.4 \%$ in the chlorthalidone and doxazosin limbs, respectively [21]) were not associated with excess mortality, either in the doxazosin arm or in comparison to other studies [37]. Heart failure was not an independent trial endpoint and events were fully validated retrospectively only in a small subgroup of 50 cases of fatal or hospitalized heart failure. Among these relatively severe cases, there were insufficient data for definitive review in 11 patients and the diagnosis was confirmed in 33 of the remaining 39 cases $(85 \%)$ [38]. Overall, therefore, the diagnosis of heart failure was only validated in $66 \%$ of a sample of the most serious cases and inaccuracies in diagnosis remains a potential source of error. It has been postulated that the early divergence of the event curves for heart failure may represent the unmasking of symptoms of heart failure (e.g. peripheral oedema) due to withdrawal of drugs (presumably mainly diuretics) in the $90 \%$ of participants who were taking antihypertensive therapy prior to randomization [37].

\section{New data on blood pressure-lowering efficacy of doxazosin GITS}

In the randomized, double-blind Doxazosin GITS as Add-on Therapy in Hypertension: an Efficacy and Safety (GATES) Study, doxazosin GITS (4 mg/day titrated to $8 \mathrm{mg} /$ day if required) or matched placebo was added to existing antihypertensive therapy of patients with uncontrolled BP. After 6 weeks, BP control $(<140 / 90 \mathrm{mmHg})$ 


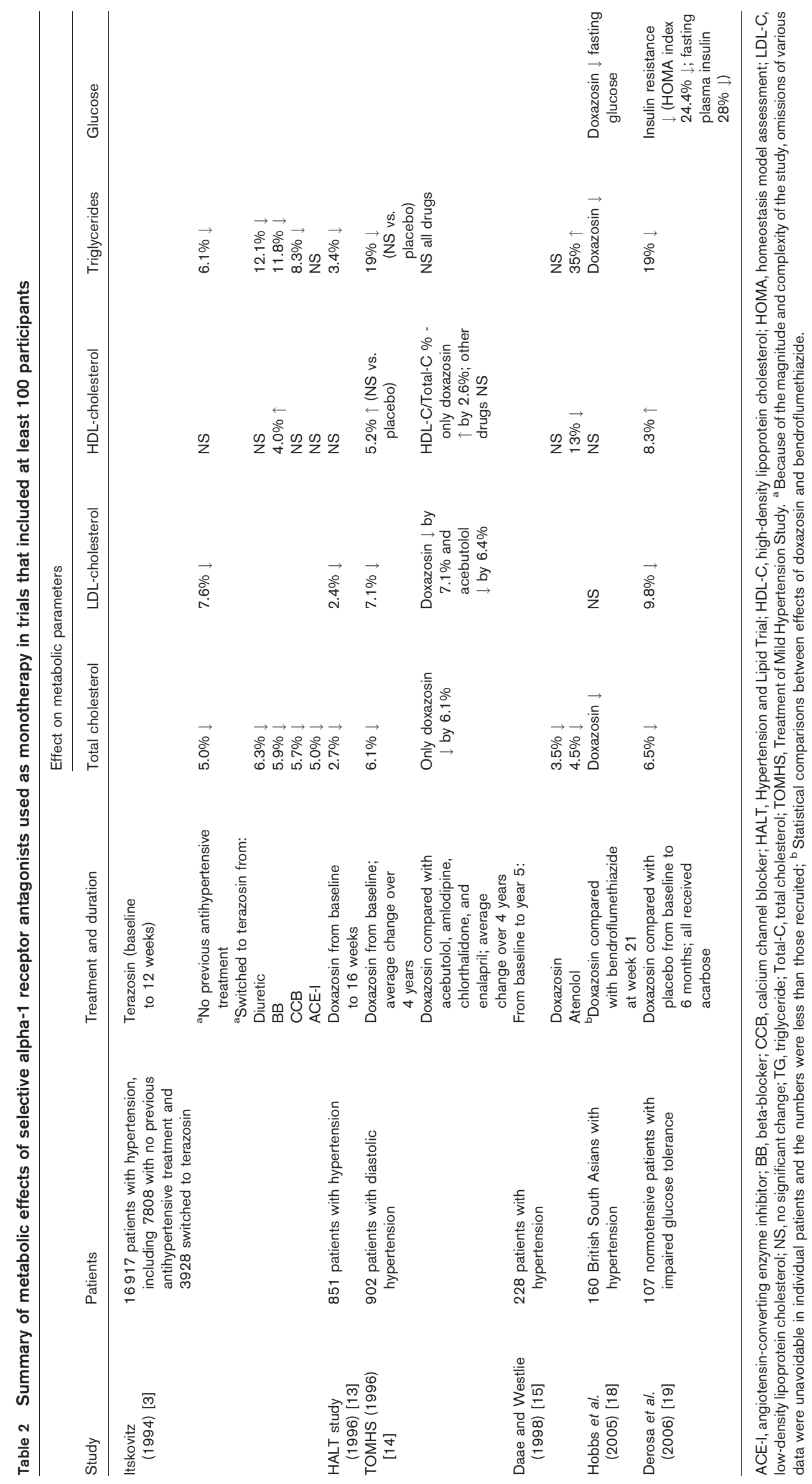


was achieved in $37.3 \%$ of those randomized to doxazosin compared with $10.7 \%$ of those receiving placebo $(P<0.001)$ [26]. The BP-lowering effects were observed in combination with all major classes of antihypertensive agents and the drug was well tolerated.

The ASOCIA ('Add-on') study was a prospective, openlabel, noncomparative study conducted among 3631 Spanish patients with uncontrolled hypertension. Participants received doxazosin GITS $(4 \mathrm{mg} /$ day titrated to $8 \mathrm{mg}$ /day if required) in addition to existing medication. The proportion reaching target $\mathrm{BP}(<140 / 90 \mathrm{mmHg})$ was $39 \%$ after 4 weeks, rising to $61 \%$ at week 16 . The drug was well tolerated with less than $3 \%$ of participants reporting adverse events [39].

\section{The Anglo-Scandinavian Cardiac Outcomes Trial \\ Blood pressure-lowering efficacy}

The Anglo-Scandinavian Cardiac Outcomes Trial was a multicentre, international, randomized trial conducted among 19257 patients aged 40-79 years with hypertension and additional cardiovascular risk factors but no history of CHD [40]. Participants were randomly assigned an antihypertensive regimen based on either amlodipine or atenolol in place of existing antihypertensive medication. Perindopril or bendroflumethiazide were added to each arm, respectively, in order to achieve target BP $(<140 / 90 \mathrm{mmHg}$ or $<130 / 80 \mathrm{mmHg}$ in those with diabetes). Doxazosin GITS could be added as a common third-line antihypertensive agent (if BP remained uncontrolled despite maximally tolerated doses of first and second-line drugs) but its use was not randomized.

Overall, 11768 participants received doxazosin GITS. In an observational database analysis, its effects were evaluated among 10069 patients (mean age 63 years, $79 \%$ male, $32 \%$ with diabetes) with valid BP measurements before and during treatment [27]. Among this group, doxazosin was initiated a median 8 months [interquartile range (IQR) 3, 24] after randomization and was added to an average of two other antihypertensive drugs; the mean starting and final doses were 4 and $7 \mathrm{mg}$, respectively. During a median 12 (IQR 4, 31) months of uninterrupted treatment (during which time there were no changes in other antihypertensive drugs or doses), mean BP fell from $159 / 89 \mathrm{mmHg}$ (SD 18/11) by almost $12 / 7 \mathrm{mmHg}$ (SD 19/10, $P<0.0001$ ). Significant reductions occurred in all patient subgroups and target $\mathrm{BP}$ was achieved in $30 \%$. Although these are uncontrolled data, they are nevertheless consistent with other studies of doxazosin GITS used as add-on antihypertensive therapy.

\section{Metabolic effects}

Analyses of lipid profiles included 2945 participants with fasting blood samples taken before and during doxazosin treatment, who took no lipid-lowering therapy and had no changes in other antihypertensives between samples [27]. During a median 9 months of uninterrupted doxazosin therapy, there were significant reductions in total cholesterol $(0.28 \mathrm{mmol} / \mathrm{l} ; 4.7 \%)$, LDL-cholesterol $(0.21 \mathrm{mmol} / \mathrm{l} ; \quad 5.5 \%)$ and triglycerides $(0.17 \mathrm{mmol} / \mathrm{l}$; 9.1\%), consistent with previous studies (see Table 2). No change in HDL-cholesterol was observed.

The effects on fasting plasma glucose were analysed in 3409 patients without diabetes prior to starting doxazosin, with fasting blood samples taken before and during doxazosin treatment, and who had no changes in other antihypertensives between samples. During a median 19 months uninterrupted doxazosin therapy, there was a small but significant increase in fasting plasma glucose (mean $0.11 \mathrm{mmol} / \mathrm{l} ; 3.5 \%$ ). This finding contradicts previous evidence that doxazosin exerts favourable effects on insulin sensitivity and glucose levels [10$12,18,19]$. However, compared with those who did not receive doxazosin in ASCO'T, recipients of doxazosin had higher systolic BP and fasting plasma glucose at study entry and were more likely to have been randomized to atenolol-based rather than amlodipine-based therapy, all of which predicted new-onset diabetes among the whole ASCO'T cohort [41]; the observed rise may therefore merely reflect the natural increase in glucose in such a population.

\section{Safety and tolerability}

All 11768 participants who received doxazosin GITS in ASCO'T contributed to analyses of safety and tolerability, accumulating 39996 patient-years of exposure to the drug [27]. In total, 1055 adverse events in 877 participants $(7.5 \%)$ resulted in temporary or permanent discontinuation of doxazosin. Of these, the most common events were dizziness (29\%), fatigue (13\%), headache (9\%), vertigo ( $9 \%)$ and oedema (8\%). Although the contribution of each drug to the overall tolerability profile of the study treatment regimen cannot be separated, these findings are consistent with other clinical data regarding doxazosin used as add-on therapy [9,26,39]. However, there still remains a relative paucity of data on its long-term safety.

\section{ASCOT, doxazosin and heart failure revisited}

In ASCOT, heart failure was a prespecified secondary endpoint with strict diagnostic criteria and all suspected cases were evaluated rigorously by an independent endpoint committee. Crude heart failure rates were $1.51 \%$ among those who received doxazosin at any point in the trial and $1.54 \%$ among the remainder. Heart failure occurred at a rate of 2.97/1000 person-years during doxazosin use, compared with $2.85 / 1000$ person-years among never users (rate ratio 1.04 , 95\% CI $0.80-1.36, P=0.76$ ). In an analysis performed in case doxazosin was stopped because of prodromal symptoms of heart failure (e.g. oedema), the rate of heart failure occurring at any point after initiation of doxazosin (whether or not it 
was continued) was $3.34 / 1000$ person-years (rate ratio $1.17,95 \%$ CI $0.92-1.49, P=0.20$, compared with never users) [27]. Therefore, although it should be reiterated that these data are nonrandomized, there appeared to be no excess of heart failure during almost 40000 patientyears exposure to doxazosin GITS. This was despite the fact that recipients of doxazosin had more severe hypertensive disease (higher systolic BP and prevalence of left ventricular hypertrophy) at study entry than the rest of the study population.

The apparent lack of an increased risk of heart failure in ASCOT is at odds with the observation of a doubled risk of CHF among those assigned doxazosin compared with those assigned chlorthalidone in ALLHAT. Whether this difference reflects the inadequacies of observational data in ASCOT (including various possible sources of bias), use of different formulations of doxazosin (modifiedrelease versus short-acting), differences between use of doxazosin as third or first-line therapy, the presence in each randomized arm of ASCOT of a drug systematically used to treat heart failure (ACE inhibitors or diuretics), the effect of withdrawal of existing diuretic therapy prior to randomization in ALLHAT, or differences in the validity of heart failure diagnosis remains unclear. However, whereas standard doxazosin used first-line may have been less effective than chlorthalidone at reducing $\mathrm{BP}$ and preventing stroke in ALLHAT, the use of the GITS formulation as third-line therapy in ASCOT was not associated with increased risk of heart failure.

\section{Hypertension treatment guidelines: changing perspectives}

As the importance of achieving and maintaining increasingly challenging BP goals has become more apparent in recent years, guidelines have placed increased emphasis placed on combination therapy. Currently, alpha-blockers have only a minor role in national and international guidelines [22,42-45] (Table 3). Their status in future guidelines is uncertain and may depend on greater confidence by prescribers regarding their safety in the addon setting.
It is worth noting, however, that whereas alpha-blockers may achieve greater endorsement as add-on therapy in the future, confidence in beta-blockers as a first-line option for uncomplicated hypertension is declining. This is due to evidence that they may not be as effective as other classes of drug in reducing cardiovascular events, particularly stroke [46], and that their use is associated with increased risk of developing new-onset diabetes, particularly when used in combination with thiazide diuretics [47]. This has been recognized in the National Institute for Health and Clinical Excellence (NICE) guidelines, which no longer recommend beta-blockers as initial therapy in uncomplicated hypertension [45].

\section{Conclusion}

Selective alpha-1 blockers lower BP and, unlike many other antihypertensives, have favourable effects on plasma lipids and glucose. Recent data have provided important information regarding their efficacy, safety and metabolic benefits, particularly of modified release doxazosin used in the add-on setting. These data suggest that doxazosin GITS is an effective third-line antihypertensive when added to a range of other drugs, improves plasma lipid profiles and is well tolerated. Recent evidence also suggests that it is not associated with increased risks of heart failure when used as add-on therapy. Whereas the lack of morbidity and mortality outcome data remains a major drawback, use of alpha-blockers seems justified, particularly in the add-on setting and in patients with metabolic complications such as dyslipidaemia or the metabolic syndrome.

\section{Contributions and acknowledgements}

Editorial assistance was provided by Pam Milner, PhD, of PAREXEL, and was funded by Pfizer Inc.

The authors developed the concept of this review during and following their round-table meeting sponsored by Pfizer Inc. in Hong Kong on 29 July 2007. The authors had full content and editorial control. Editorial assistance was funded by Pfizer Inc.

Table 3 Summary of major guidelines for use of alpha-1 adrenoceptor antagonists for hypertension

\begin{tabular}{|c|c|c|}
\hline Guideline & Year & Recommendation for use of alpha-blockers \\
\hline $\begin{array}{l}\text { Seventh report of the Joint National Committee } \\
\text { on prevention, detection, evaluation and } \\
\text { treatment of high blood pressure (JNC 7) [22] }\end{array}$ & 2003 & $\begin{array}{l}\text { Included in list of oral antihypertensive agents but place } \\
\text { in therapy not defined }\end{array}$ \\
\hline $\begin{array}{l}\text { Joint British Societies, guidelines on prevention } \\
\text { of cardiovascular disease in clinical practice (JBS-2) [42] }\end{array}$ & 2005 & $\begin{array}{l}\text { Benign prostatic hyperplasia (BPH) listed as a } \\
\text { compelling indication } \\
\text { Caution advised in patients with postural hypotension } \\
\text { and heart failure } \\
\text { Contraindicated in urinary incontinence }\end{array}$ \\
\hline $\begin{array}{l}\text { European Society of Hypertension/European } \\
\text { Society of Cardiology (ESH/ESC) [43] }\end{array}$ & 2007 & $\begin{array}{l}\text { Mentioned as frequently used add-on therapy } \\
\text { Benign prostatic hyperplasia listed as a specific indication }\end{array}$ \\
\hline British Hypertension Society (BHS) [44] & 2004 & $\begin{array}{l}\text { Recommended as } 4^{\text {th }} \text {-line therapy } \\
\text { Benign prostatic hyperplasia listed as a compelling indication }\end{array}$ \\
\hline National Institute for Health and Clinical Excellence (NICE) [45] & 2006 & Recommended as fourth-line therapy \\
\hline
\end{tabular}


Conflicts of interest: N.C. reports receiving speaker fees from Pfizer and Novartis and consultancy fees from Servier.

C.-Y.C. reports receiving fees for moderatorship as well as speaker fees from Pfizer, Novartis, Merck-ScheringPlough and AstraZeneca.

F.D.R.H. reports receiving sponsorship or speaker/consulting fees from Astra-Zeneca, Pfizer, Sanofi, Boeringer, Merck, Roche Diagnostics and Takeda and research funding from Pfizer and Roche Diagnostics in past 3 years.

J.-C.W. reports receiving lecture fees from Astra-Zeneca, Novartis, Pfizer, and Servier.

B.W. has received honoraria for lectures at congresses and symposia supported by Pfizer.

T.F., S.J.K. and S.T. report no conflicts of interest.

\section{References}

1 Fukiyama K, Omae T, limura O, Yoshinaga K, Yagi S, Inagaki Y, et al. A double-blind comparative study of doxazosin and prazosin in the treatment of essential hypertension. Am Heart J 1991; 121:317-322.

2 Sega R, Marazzi ME, Bombelli M, Vulpis V, Antonacci A, Leto di Priolo S, et al. Comparison of the new alpha-1 blocker alfuzosin with propranolol as first-line therapy in hypertension. Pharmacol Res 1991; 24:41-52.

3 Itskovitz HD. Alpha 1-blockade for the treatment of hypertension: a megastudy of terazosin in 2214 clinical practice settings. Clin Ther 1994; 16:490-504.

4 Joglekar SJ, Nanivadekar AS. A randomized, controlled, multicenter study to compare prazosin GITS with enalapril in hypertensive patients with diabetes mellitus. J Assoc Physicians India 1998; (Suppl 1): 52-62.

5 Neaton JD, Grimm RH Jr, Prineas RJ, Stamler J, Grandits GA, Elmer PJ, et al. Treatment of Mild Hypertension Study. Final results. J Am Med Assoc 1993; 270:713-724.

6 Os I, Stokke HP. Effects of doxazosin in the gastrointestinal therapeutic system formulation versus doxazosin standard and placebo in mild-tomoderate hypertension. Doxazosin Investigators' Study Group. J Cardiovasc Pharmacol 1999; 33:791-797.

7 Calvo C, Gil-Extremera B, Gomez-Fernández P, Masramon X, Pueyo C, Armada B. Doxazosin GITS versus standard doxazosin in mild to moderate hypertension. Int J Cardiol 2005; 101:97-104.

8 Os I. Comparison of doxazosin GITS and standard doxazosin in the treatment of high blood pressure. Int J Clin Pharmacol Ther 2006; 44:99-106.

9 Black HR, Sollins JS, Garofalo JL. The addition of doxazosin to the therapeutic regimen of hypertensive patients inadequately controlled with other antihypertensive medications: a randomized, placebo-controlled study. Am J Hypertens 2000; 13:468-474.

10 Lehtonen A. Doxazosin effects on insulin and glucose in hypertensive patients. The Finnish Multicenter Study Group. Am Heart J 1991; 121:1307-1311.

11 Huupponen R, Lehtonen A, Vahatalo M. Effect of doxazosin on insulin sensitivity in hypertensive noninsulin dependent diabetic patients. Eur J Clin Pharmacol 1992; 43:365-368.

12 Maheux P, Facchini F, Jeppesen J, Greenfield MS, Clinkingbeard C, Chen YD, Reaven GM. Changes in glucose, insulin, lipid, lipoprotein, and apoprotein concentrations and insulin action in doxazosin-treated patients with hypertension. Comparison between nondiabetic individuals and patients with noninsulin-dependent diabetes mellitus. Am J Hypertens $1994 ; 7: 416-424$.

13 Levy D, Walmsley P, Levenstein M. Principal results of the Hypertension and Lipid Trial (HALT): a multicenter study of doxazosin in patients with hypertension. Am Heart J 1996; 131:966-973.

14 Grimm RH Jr, Flack JM, Grandits GA, Elmer PJ, Neaton JD, Cutler JA, et al. Long-term effects on plasma lipids of diet and drugs to treat hypertension. Treatment of Mild Hypertension Study (TOMHS) Research Group. J Am Med Assoc 1996; 275:1549-1556.
15 Daae LN, Westlie L. A 5-year comparison of doxazosin and atenolol in patients with mild-to-moderate hypertension: effects on blood pressure, serum lipids, and coronary heart disease risk. Blood Press 1998; 7:39-45.

16 Hirano T, Yoshino G, Kashiwazaki K, Adachi M. Doxazosin reduces prevalence of small dense low density lipoprotein and remnant-like particle cholesterol levels in nondiabetic and diabetic hypertensive patients. Am J Hypertens 2001; 14:908-913.

17 Kinoshita M, Shimazu N, Fujita M, Fujimaki Y, Kojima K, Mikuni Y, et al. Doxazosin, an alpha1-adrenergic antihypertensive agent, decreases serum oxidized LDL. Am J Hypertens 2001; 14:267-270.

18 Hobbs FR, Khan T, Collins B. Doxazosin versus bendrofluazide: a comparison of the metabolic effects in British South Asians with hypertension. Br J Gen Pract 2005; 55:437-443.

19 Derosa G, Cicero AF, D'Angelo A, Ragonesi PD, Ciccarelli L, Fogari E, et al. Synergistic effect of doxazosin and acarbose in improving metabolic control in patients with impaired glucose tolerance. Clin Drug Investig 2006; 26:529-539.

20 Lepor $\mathrm{H}$. Role of alpha adrenergic blockers in the treatment of benign prostatic hypertrophy. Prostate Supp/ 1990; 3:75-84.

21 The ALLHAT Officers and Coordinators for the ALLHAT Collaborative Research Group. Major cardiovascular events in hypertensive patients randomized to doxazosin vs. chlorthalidone: the Antihypertensive and LipidLowering Treatment to Prevent Heart Attack Trial (ALLHAT). J Am Med Assoc 2000; 283:1967-1975.

22 Chobanian AV, Bakris GL, Black HR, Cushman WC, Green LA, Izzo JL Jr, et al. Seventh report of the Joint National Committee on Prevention, Detection, Evaluation, and Treatment of High Blood Pressure. Hypertension 2003; 42:1206-1252.

23 O'Callaghan CJ, Williams B. The regulation of human vascular smooth muscle extracellular matrix protein production by alpha- and betaadrenoceptor stimulation. J Hypertens 2002; 20:287-294.

24 Iwamoto N, Abe-Dohmae S, Ayaori M, Tanaka N, Kusuhara M, Ohsuzu F, et al. ATP-binding cassette transporter A1 gene transcription is downregulated by activator protein 2alpha. Doxazosin inhibits activator protein 2alpha and increases high-density lipoprotein biogenesis independent of alpha1-adrenoceptor blockade. Circ Res 2007; 101: 156-165.

25 Black HR. Doxazosin as combination therapy for patients with stage and stage 2 hypertension. J Cardiovasc Pharmacol 2003; 41:866869.

26 Black HR, Keck M, Meredith P, Bullen K, Quinn S, Koren A. Controlledrelease doxazosin as combination therapy in hypertension: the GATES study. J Clin Hypertens (Greenwich) 2006; 8:159-166.

27 Chapman N, Chang CL, Dahlof B, Sever PS, Wedel H, Poulter NR, ASCOT Investigators. Effect of doxazosin gastrointestinal therapeutic system as third-line antihypertensive therapy on blood pressure and lipids in the Anglo-Scandinavian Cardiac Outcomes Trial. Circulation 2008; 118:42-48.

28 Kanagy NL. Alpha(2)-adrenergic receptor signalling in hypertension. Clin Sci (Lond) 2005; 109:431-437.

29 Sonders RC. Pharmacokinetics of terazosin. Am J Med 1986; 80 (Suppl 5B):20-22.

30 DiPiro JT. Controlling drug effects through improved oral formulations. The pharmacokinetics of the prazosin gastrointestinal therapeutic system. Am J Med 1989; 87:31S-35S.

31 Fourtillan JB, Brisson AM, Couet W. Pharmacokinetics of prazosin administered as gastrointestinal-therapeutics-systems to 24 healthy volunteers. Therapie 1993; 48:115-118.

32 Chung M, Vashi V, Puente J, Sweeney M, Meredith P. Clinical pharmacokinetics of doxazosin in a controlled-release gastrointestinal therapeutic system (GITS) formulation. Br J Clin Pharmacol 1999; 48:678-687.

33 Hermida RC, Calvo C, Ayala DE, Dominguez MJ, Covelo M, Fernandez JR, et al. Administration-time-dependent effects of doxazosin GITS on ambulatory blood pressure of hypertensive subjects. Chronobiol Int 2004; 21:277-296.

34 Kario K, Schwartz JE, Pickering TG. Changes of nocturnal blood pressure dipping status in hypertensives by nighttime dosing of alpha-adrenergic blocker, doxazosin: results from the HALT study. Hypertension 2000; 35:787-794.

35 Grimm RH Jr, Grandits GA, Prineas RJ, McDonald RH, Lewis CE, Flack JM, et al. Long-term effects on sexual function of five antihypertensive drugs and nutritional hygienic treatment in hypertensive men and women. Treatment of Mild Hypertension Study (TOMHS). Hypertension 1997; 29:8-14.

36 Messerli FH. Implications of discontinuation of doxazosin arm of ALLHAT Antihypertensive and Lipid-Lowering Treatment to Prevent Heart Attack Trial. Lancet 2000; 355:863-864. 
37 Poulter N, Williams B. Doxazosin for the management of hypertension: implications of the findings of the ALLHAT trial. Am J Hypertens 2001; 14:1170-1172.

38 Pillar LB, Davis BR, Cutler JA, Cushman WC, Wright JT Jr, Williamson JD, et al. Validation of heart failure events in the Antihypertensive and Lipid Lowering Treatment to Prevent Heart Attack Trial (ALLHAT) participants assigned to doxazosin and chlorthalidone. Curr Control Trials Cardiovasc Med 2002; 3:10.

39 de Alvaro F, Hernández-Presa MA, ASOCIA Study. Effect of doxazosin gastrointestinal therapeutic system on patients with uncontrolled hypertension: the ASOCIA Study. J Cardiovasc Pharmacol 2006; 47:271-276.

40 Sever PS, Dahlof B, Poulter NR, Wedel H, Beevers G, Caulfield M, et al. Rationale, design, methods and baseline demography of participants of the Anglo-Scandinavian Cardiac Outcomes Trial. J Hypertens 2001; 19:11391147.

41 Gupta AK, Dahlof B, Dobson J, Sever PS, Wedel H, Poulter NR, AngloScandinavian Cardiac Outcomes Trial Investigators. Determinants of new onset diabetes among 19,257 hypertensive patients randomized in the Anglo-Scandinavian Cardiac Outcomes Trial-blood pressure lowering arm and the relative influence of antihypertensive medication. Diabetes Care 2008; 31:982-988
42 British Cardiac Society, British Hypertension Society, Diabetes UK, HEART UK, Primary Care Cardiovascular Society, The Stroke Association. JBS 2: Joint British Societies' guidelines on prevention of cardiovascular disease in clinical practice. Heart 2005; 91(Suppl 5):v1-v52.

43 Mancia G, De Backer G, Dominiczak A, Cifkova R, Fagard R, Germano G, et al. 2007 Guidelines for the Management of Arterial Hypertension: The Task Force for the Management of Arterial Hypertension of the European Society of Hypertension (ESH) and of the European Society of Cardiology (ESC). J Hypertens 2007; 25:1105-1187.

44 Williams B, Poulter NR, Brown MJ, Davis M, Mclnnes GT, Potter JF, et al. Guidelines for management of hypertension: report of the fourth working party of the British Hypertension Society, 2004-BHS IV. J Hum Hypertens 2004; 18:139-185.

45 National Institute for Health and Clinical Excellence (NICE). Hypertension: management of hypertension in adults in primary care. NICE web site. Accessed on February 11, 2008 from: http://www.nice.org.uk/guidance/CG34.

46 Lindholm LH, Carlberg B, Samuelsson O. Should beta blockers remain first choice in the treatment of primary hypertension? A meta-analysis. Lancet 2005; 366:1545-1553.

47 Mason JM, Dickinson HO, Nicolson DJ, Campbell F, Ford GA, Williams B. The diabetogenic potential of thiazide-type diuretic and beta-blocker combinations in patients with hypertension. J Hypertens 2005; 23:1777-1781. 